\title{
The biomarker TP53 divides patients with neoadjuvantly treated esophageal cancer into 2 subgroups with markedly different outcomes. A p53 Research Group study
}

\author{
Daniela Kandioler, MD, MBA, ${ }^{\mathrm{a}}$ Sebastian F. Schoppmann, MD, ${ }^{\mathrm{a}, \mathrm{b}}$ Ronald Zwrtek, MD, \\ Sonja Kappel, $\mathrm{PhD},{ }^{\mathrm{a}, \mathrm{d}}$ Brigitte Wolf, $\mathrm{PhD},{ }^{\mathrm{a}, \mathrm{d}}$ Martina Mittlböck, $\mathrm{PhD},{ }^{\mathrm{e}}$ Irene Kührer, MD ${ }^{\mathrm{f}}$ \\ Michael Hejna, MD, ${ }^{\mathrm{f}}$ Ursula Pluschnig, MD, ${ }^{\mathrm{f}}$ Ahmed Ba-Ssalamah, MD, ${ }^{\mathrm{g}}$ Fritz Wrba, MD, ${ }^{\mathrm{h}}$ and \\ Johannes Zacherl, $\mathrm{MD}^{\mathrm{a}}$
}

\begin{abstract}
Background: Fluorouracil and cisplatin have been used most frequently as neoadjuvant therapy for esophageal cancer. Both drugs are believed to act via a p53-dependent apoptosis pathway. The TP53 gene is frequently mutated in esophageal cancer.
\end{abstract}

Objective: To test the value of TP53 as a biomarker prognosing outcome in patients with neoadjuvantly treated esophageal cancer.

\begin{abstract}
Patients and Methods: The investigation included 36 patients with primary operable esophageal cancer who were treated neoadjuvantly with cisplatin and fluorouracil. The TP53 genotype was assessed from paraffinembedded diagnostic tumor biopsies using a standardized gene-specific TP53 sequencing protocol (mark53 kit; mark53 Ltd, Vienna, Austria).
\end{abstract}

\begin{abstract}
Results: Mutations in the TP53 gene were present in 50\% of tumors. Two-year overall survival rates were 55.6\% in patients with a normal TP53 marker status, compared with $16.7 \%$ in those with a mutant TP53 gene. In patients with normal TP53, neoadjuvant treatment resulted in significant advantages in terms of tumor-associated survival $(P=.0049)$ and overall survival $(P=.0304)$ compared with those with mutant $T P 53$. The median tumorassociated survival was 34.2 months for patients with normal TP53, compared with 8.9 months for those with mutant TP53. The latter had a 3-fold higher risk of dying (hazard ratio, 3.01; 95\% confidence interval, 1.359-6.86).
\end{abstract}

Conclusions: The biomarker TP53 divides esophageal cancer patients into 2 categories with markedly different outcomes: patients with a normal TP53 marker status may experience notable benefits from neoadjuvant chemotherapy with cisplatin/fluorouracil, whereas those with a mutant TP53 marker status appear to be at risk for lack of response. (J Thorac Cardiovasc Surg 2014;148:2280-6)

See related commentary on pages 2286-7.

In patients with esophageal cancer, fluorouracil and cisplatin have been used as the standard preoperative chemotherapy regimen. A recent meta-analysis ${ }^{1}$ indicated

\footnotetext{
From the Department of Surgery, ${ }^{\text {a }}$ Comprehensive Cancer Center-GI Tumor Unit, ${ }^{b}$ Surgical Research, ${ }^{\mathrm{d}}$ Center for Medical Statistics, Informatics, and Intelligent Systems, Section for Clinical Biometrics, ${ }^{\mathrm{e}}$ Department of Internal Medicine I, ${ }_{\mathrm{f}}^{\mathrm{f}}$ Department of Radiology, ${ }^{\mathrm{g}}$ and Department of Clinical Pathology, ${ }^{\mathrm{h}}$ Medical University of Vienna, Vienna, Austria; and the Department of Surgery, ${ }^{\mathrm{c}}$ Landesklinikum Sankt Poelten, Sankt Poelten, Austria.

Disclosures: Martina Mittlböck reports consutling fees from Actelion, equity ownership in Intercell, and lecture fees from Bayer. Johannes Zacherl reports lecture fees from Olympus, Nestle, Covidien, Novartis, and AFS. All other authors have nothing to disclose with regard to commercial support.

Received for publication Sept 5, 2013; revisions received April 14, 2014; accepted for publication June 12, 2014; available ahead of print Aug 16, 2014.

Address for reprints: Daniela Kandioler, MD, MBA, Department of Surgery, Medical University of Vienna, Waehringer Guertel 18-20, 1090 Vienna, Austria (E-mail: daniela.kandioler@meduniwien.ac.at).

0022-5223/\$36.00

Copyright (c) 2014 by The American Association for Thoracic Surgery

http://dx.doi.org/10.1016/j.jtcvs.2014.06.079
}

a marginal survival benefit for preoperative chemotherapy with cisplatin/fluorouracil compared with surgery alone in patients with resectable esophageal cancer. Survival appears to be most significantly improved in patients experiencing complete histopathologic response. ${ }^{2,3}$ However, complete response rarely occurs under this regimen $(5 \%$ $15 \%$ ) and currently responders cannot be identified before treatment. The use of more intensive regimens to improve complete response rates appeared to be limited by the concomitant increase in treatment-related morbidity and mortality. ${ }^{4}$

Markers predicting response to chemotherapy would greatly enhance the efficacy of treatment and simultaneously reduce chemotherapy-related risks by permitting individualized preoperative treatment. No such predictive markers have been established for esophageal cancer.

P53 has been suggested to play a crucial role in a patient's response to various chemotherapeutic regimens. Defective TP53 has been considered a plausible reason for drug resistance, thus permitting response prediction. ${ }^{5}$ Chemotherapy drugs such as cisplatin and fluorouracil act by inducing DNA damage. The latter is the strongest trigger for the 


\section{Abbreviations and Acronyms \\ $\mathrm{CR}=$ complete remission \\ CROSS = Neoadjuvant Chemoradiation Followed by Surgery versus Surgery Alone for \\ Patients with Adenocarcinoma or \\ Squamous Cell Carcinoma of the Esophagus \\ PANCHO $=$ p53-Adjusted Neoadjuvant \\ Chemotherapy for Potentially \\ Resectable Esophageal Cancer \\ PET = positron emission tomography}

activation of the TP53 gene. As a result p53 transactivates genes of the apoptotic cascade resulting in programmed cell death. However, because TP53 is the most frequently mutated gene associated with cancer, this pathway is often disrupted. ${ }^{6}$

We hypothesized that p53 mutation status may be useful for prognosing outcome in patients with resectable esophageal cancer treated with neoadjuvant chemotherapy. The aim of the study was to evaluate the association of response to neoadjuvant cisplatin/fluorouracil in patients with esophageal cancer stratified for the tumor's TP53 status.

\section{METHODS}

Patients with primary operable esophageal cancer and treated by neoadjuvant chemotherapy were included in this phase II biomarker study. From August 2001 to May 2007, we identified 47 consecutive patients who received neoadjuvant treatment at 2 institutions.

Neoadjuvant treatment consisted of 2 cycles of chemotherapy with cisplatin $80 \mathrm{mg} / \mathrm{m}^{2}$ as an intravenous infusion over 4 hours on day 1 , and fluorouracil $1000 \mathrm{mg} / \mathrm{m}^{2}$ as a continuous infusion on day 1 and day $14 \mathrm{in}$ 36 patients. The neoadjuvant regimen is based on the results of the United Kingdom Medical Research Council esophageal cancer trial. ${ }^{7}$ Eleven patients who received a different treatment were excluded.

The study was approved by the local ethics committee and included informed consent for DNA testing.

Staging was performed before and after neoadjuvant chemotherapy to determine operability. Clinical staging included computed tomography of the abdomen, chest, and neck; endoscopy/biopsy of the upper gastrointestinal tract; as well as a positron emission tomography (PET) scan in some patients and bronchoscopy in patients with squamous cell carcinoma.

Computed tomography scans were used to determine the patients' resectability and the tumor mass at initial staging and preoperative restaging. Data from fluordeoxyglucose PET scans were available for 10 patients. The remaining patients had either no PET on the day of staging and/or restaging. Thus we did not include this information in our analysis.

At restaging 7 patients had criteria of inoperability after neoadjuvant chemotherapy; local progression was seen in 4 patients who therefore had exploration only. De novo distant metastases were detected in 3 patients who were excluded from surgery. Although these 7 patients had no complete tumor resection, they were not excluded from survival analysis; tumor progression during chemotherapy is a clear indicator of treatment failure. Thus we believe that the exclusion of these patients would have biased the survival comparisons for the assessment of TP53 as a biomarker predicting response to treatment.

The major outcome measures were response as determined by overall survival, tumor-associated survival, and objective tumor response.
Additionally objective tumor response was measured in terms of a change in the size of the tumor. Computed tomography scans were used to measure tumor mass at initial pretreatment staging and at restaging (before surgery). Complete remission (CR) was defined as complete absence of tumor, confirmed by histologic investigation of the surgical specimen. Partial response was defined as major or obvious response, expressed as a minimum reduction of $30 \%$ in tumor mass. Progressive disease was defined as an increase in tumor mass or the appearance of new peripheral lesions.

For analysis of the TP53 genotype, tumor DNA was extracted from paraffin-embedded tissue of the diagnostic tumor biopsies. The patients' marker status was assessed with a standardized gene-specific sequencing kit for the p53 gene (mark53 kit; mark53 Ltd, Vienna, Austria).

Mutations in the $\mathrm{p} 53$ gene were reported according to the recommendations of the Human Genome Variation Society (www.hgvs.org). ${ }^{8}$

Silent mutations were rated normal.

\section{Statistical Analysis}

Continuous data are described with mean and standard deviation in cases of normal distribution or by median, minimum, and maximum otherwise. Differences between groups were tested by independent samples $t$ test in case of normal distribution and by Wilcoxon rank-sum test otherwise. Categorical data are described with absolute and relative frequencies. A $\chi^{2}$ test was used to assess for group differences for binary and nominal variables. For ordinal variables a trend $\chi^{2}$ test was used. In case of sparse data the Fisher exact test or exact $\chi^{2}$ tests were used.

Surgical mortality included all deaths within 30 days after the operation or during hospitalization.

The primary outcome measure was overall survival, tumor-associated survival, and treatment response. Overall survival and tumor-associated survival are defined from the date of the first cycle of neoadjuvant chemotherapy until death or last time known to be alive. Overall survival included all deaths, independent of the cause. Median follow-up time was calculated by Kaplan-Meier method where deaths are censored for further follow-up. Survival probabilities were estimated by Kaplan-Meier graphs and group differences were assessed by log-rank test. The Cox regression model was used to assess group differences by hazard ratios (HRs) and corresponding $95 \%$ confidence intervals (CIs). Multiple Cox regression models were fitted to assess the influence of TP53 on survival additional to standard prognostic factors to evaluate if TP53 is an independent prognostic factor. However this overfitted model cannot be seen as prognostic model for future patients.

Statistical calculations are performed with SAS (SAS Institute Inc, Cary, NC) and SPSS (IBM-SPSS Inc, Armonk, NY). All $P$ values are 2sided and $P \leq .05$ was considered significant.

\section{RESULTS \\ Patients}

Thirty-six patients with primary operable esophageal cancer who had received neoadjuvant treatment with fluorouracil and cisplatin were evaluated for their TP53 status. The TP53 mutation rate in the study cohort was 50\% (18 out of 36). TP53 mutations are described in Table 1. Pretreatment patient characteristics are shown in Table 2.

At the time of evaluation, after a median follow-up of 87.4 months (7.3 years), 33 of 36 patients were dead (91.7\%) (Figure 1). Seven patients died from nontumor-related causes: of these 3 died perioperatively due to acute respiratory distress syndrome, pneumonia, or anastomosis failure; 2 patients died as a result of stroke; 1 died due to sepsis; and in 1 patient the cause of death was unknown. Three patients are still alive and were censored between 79 and 96 months. One half of patients survived for longer than 13.9 months. 
TABLE 1. TP53 mutations in patients with esophageal cancer

\begin{tabular}{|c|c|c|}
\hline Patient no. & Exon & TP53 mutation* \\
\hline 1807 & 5 & c. $422 \mathrm{G}>\mathrm{A}$ (p.Cys141Tyr) \\
\hline 1789 & 5 & c. $452 C>G$ (p.Pro151Arg) \\
\hline 1794 & 5 & c.469G > T (p.Val157Phe) \\
\hline 2047 & 5 & c. $514 \mathrm{G}>\mathrm{T}$ (p.Val172Phe) \\
\hline 1916 & 6 & c.569dupC (p.Pro191SerfsX18) \\
\hline 1811 & 6 & c.635_636delTT (p.Phe212SerfsX3) \\
\hline 1804 & 6 & c.659A >G (p.Tyr220Cys) \\
\hline 1797 & 7 & c.707A>G (p.Tyr236Cys) \\
\hline 1837 & 7 & c.713delG (p.Cys238LeufsX9) \\
\hline 1809 & 7 & c.743G $>$ A (p.Arg248Gln) \\
\hline 1833 & 7 & c. $742 \mathrm{C}>\mathrm{T}$ (p.Arg248Trp) \\
\hline 1798 & 8 & c.811G $>$ A (p.Glu271Lys) \\
\hline 1800 & 8 & c.818G $>$ A (p.Arg273His) \\
\hline 1579 & 8 & c.818G $>$ A (p.Arg273His) \\
\hline 1805 & 8 & c.824G $>$ A (p.Cys275Tyr) \\
\hline 2048 & 8 & c.833C $>$ G (p.Pro278Arg) \\
\hline 1810 & 8 & c. $844 C>$ T (p.Arg $282 \operatorname{Trp})$ \\
\hline 1802 & 8 & c.916C > T (p.Arg306X) \\
\hline
\end{tabular}

*Reported according to Recommendations of the Human Genome Variation Society (www.hgvs.org). ${ }^{8}$

\section{Complete Remission After Neoadjuvant Chemotherapy}

CR (2 pathologic and 1 clinical) occurred in $9 \%$ of patients ( 3 out of 36). The patient with clinical CR at restaging refused to undergo surgery (Table 3). Pathologic CR

TABLE 2. Pretreatment patient characteristics

\begin{tabular}{|c|c|c|c|c|}
\hline Characteristic & $\begin{array}{c}\text { TP53 } \\
\text { normal }\end{array}$ & $\begin{array}{c}\text { TP53 } \\
\text { mutated }\end{array}$ & Total & $P$ value \\
\hline TP53 genotype & 18 & 18 & 36 & \\
\hline \multicolumn{5}{|l|}{ Sex } \\
\hline Male & 15 & 15 & 30 & \\
\hline Female & 3 & 3 & 6 & 1.000 \\
\hline Age, y $($ mean \pm SD) & $60.4 \pm 8.0$ & $64.2 \pm 7.9$ & $62.3 \pm 8.1$ & .1619 \\
\hline \multicolumn{5}{|l|}{ Tumor type } \\
\hline Adenocarcinoma & 11 & 9 & 20 & \\
\hline $\begin{array}{l}\text { Squamous cell } \\
\text { carcinoma }\end{array}$ & 7 & 9 & 16 & .5023 \\
\hline \multicolumn{5}{|l|}{ Clinical tumor staging } \\
\hline $\mathrm{T} 0 /$ carcinoma in situ & 0 & 0 & 0 & \\
\hline $\mathrm{T} 1$ & 0 & 2 & 2 & \\
\hline $\mathrm{T} 2$ & 6 & 5 & 11 & \\
\hline $\mathrm{T} 3$ & 9 & 9 & 18 & .7994 \\
\hline $\mathrm{T} 4$ & 0 & 1 & 1 & \\
\hline Missing* & 3 & 1 & 4 & \\
\hline NO & 7 & 3 & 10 & \\
\hline N1 & 8 & 14 & 22 & .1283 \\
\hline Missing* & 3 & 1 & 4 & \\
\hline Gx & & & 0 & \\
\hline G1 & 1 & 1 & 2 & \\
\hline $\mathrm{G} 2$ & 6 & 10 & 16 & \\
\hline G3 & 6 & 7 & 13 & 1.000 \\
\hline Missing* & 5 & 0 & 5 & \\
\hline
\end{tabular}

$S D$, Standard deviation. *Missing values in TN staging are due to stent implantation before computed tomography.

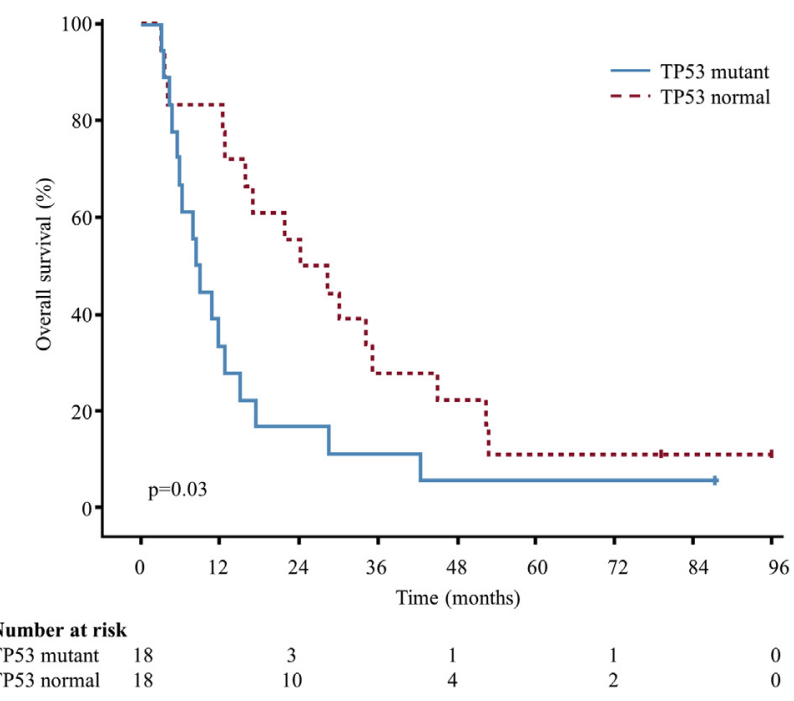

FIGURE 1. Overall survival in patients with normal TP53 versus mutant TP53.

includes 1 patient with yT0 and 1 patient with carcinoma in situ. All CRs occurred in patients with TP53 normal tumors, whereas there was no CR observed in patients with TP53 mutant tumors (Table 3).

\section{Survival by TP53 Mutation}

Neoadjuvant treatment with cisplatin/fluorouracil resulted in a significant benefit for overall survival $(P=.0304)$ and tumor-associated survival $(P=.0049)$ in patients with a normal TP53 status compared with those with a mutant TP53 status (Figures 1 and 2).

Overall survival is shown in Figure 1. Median overall survival was 8.6 months for patients with mutated TP53 and 26.2 months for patients with nonmutated TP53, which corresponds to an HR of 2.15 (95\% CI, 1.06-4.38).

Tumor-associated survival is shown in Figure 2. Median tumor-associated survival was 8.9 months for patients with mutated TP53 and 34.2 months for nonmutated patients, which corresponds to an HR of $3.01(95 \% \mathrm{CI}$, 1.36-6.86).

Multiple Cox regression models were fitted to assess the influence of TP53 on survival additional to the standard prognostic factors shown in Table 2 to evaluate if TP53 is an independent prognostic factor. Despite the overfit of the model, patients with TP53 mutations still showed a significantly higher risk for shorter overall survival (HR, 4.075; 95\% CI, 1.209-13.737; $P=.0235$ ) and tumor-associated survival (HR, 7.417; 95\% CI, $1.974-$ 27.876; $P=.0030$ ) additional to the standard prognostic factors.

\section{Adenocarcinoma Versus Squamous Cell Carcinoma}

Sixteen cases of squamous cell carcinoma and 20 cases of adenocarcinoma were included in our investigation. Of the 
TABLE 3. Posttreatment patient characteristics

\begin{tabular}{|c|c|c|c|c|}
\hline Characteristic & TP53 normal & TP53 mutated & Total & $P$ value \\
\hline \multicolumn{5}{|l|}{ Pathologic tumor staging } \\
\hline yT0 & 1 & 0 & 1 & \\
\hline Carcinoma in situ & 1 & 0 & 1 & \\
\hline yT1 & 3 & 2 & 5 & \\
\hline yT2 & 3 & 4 & 7 & \\
\hline yT3 & 9 & 4 & 13 & \\
\hline yT4 & 0 & 0 & 0 & .8471 \\
\hline Missing & 1 & 8 & 9 & \\
\hline No & 7 & 3 & 10 & \\
\hline $\mathrm{N} 1$ & 10 & 7 & 17 & 6919 \\
\hline Missing & 1 & 8 & 9 & \\
\hline Gx & 1 & 0 & 1 & \\
\hline G1 & 2 & 3 & 5 & \\
\hline G2 & 8 & 5 & 13 & \\
\hline G3 & 6 & 2 & 8 & .6282 \\
\hline Missing & 1 & 8 & 9 & \\
\hline \multicolumn{5}{|l|}{ Adapted pathologic tumor staging* } \\
\hline Carcinoma in situ & 2 & 0 & & \\
\hline yTIS & 1 & 0 & & \\
\hline yT1 & 3 & 2 & & \\
\hline yT2 & 3 & 4 & & \\
\hline yT3 & 9 & 4 & & \\
\hline Adapted T4 & 0 & 8 & & \\
\hline Adapted missing & 0 & 0 & & .0191 \\
\hline \multicolumn{5}{|l|}{ Surgery } \\
\hline Mean number (range) of resected lymph nodes & $17(10-43)$ & $16(5-28)$ & $16(5-43)$ & .4598 \\
\hline \multicolumn{5}{|l|}{ Resection } \\
\hline Radical & 15 & 9 & 24 & \\
\hline R1 & 2 & 1 & 3 & \\
\hline No resection & 1 & 8 & 9 & .0236 \\
\hline \multicolumn{5}{|l|}{ Reasons for no resection } \\
\hline Complete tumor remission/refused surgery & 1 & 0 & 1 & \\
\hline Clinical progression, poor condition & 0 & 1 & 1 & \\
\hline Inoperability due to local progression & 0 & 4 & 4 & \\
\hline Inoperable due to systemic progression & 0 & 3 & 3 & \\
\hline \multicolumn{5}{|l|}{ Nontumor-related deaths } \\
\hline Pneumonia & 2 & 1 & 3 & \\
\hline Other & 3 & 1 & 4 & \\
\hline \multicolumn{5}{|l|}{ Response } \\
\hline Complete remission $\dagger$ & 3 & 0 & 3 & \\
\hline Partial remission & 14 & 4 & 18 & \\
\hline Stable disease & 1 & 6 & 7 & \\
\hline Progressive disease & 0 & 8 & 8 & $<.0001$ \\
\hline
\end{tabular}

3 patients with CR, 2 had squamous cell carcinoma and 1 had adenocarcinoma. There was no difference in the frequency of TP53 mutation between the 2 histologic types (Table 2). Tumor-associated overall survival did not differ in the 2 histologic types $(P=.4102)$. For both histologic types, tumor-associated survival was improved in patients with normal TP53 (adenocarcinoma $P=.0042$; squamous cell carcinoma $P=.0615)$.

\section{Surgery}

A transthoracic resection was performed in 13 patients, a transhiatal resection was performed in 12 patients, and 2 patients underwent extended gastrectomy. Posttreatment patient characteristics are shown in Table 3.

Nine patients had no curative resection. Therefore we had 9 missing values for pathologic staging. With 9 missing values in the calculation no statistically significant 


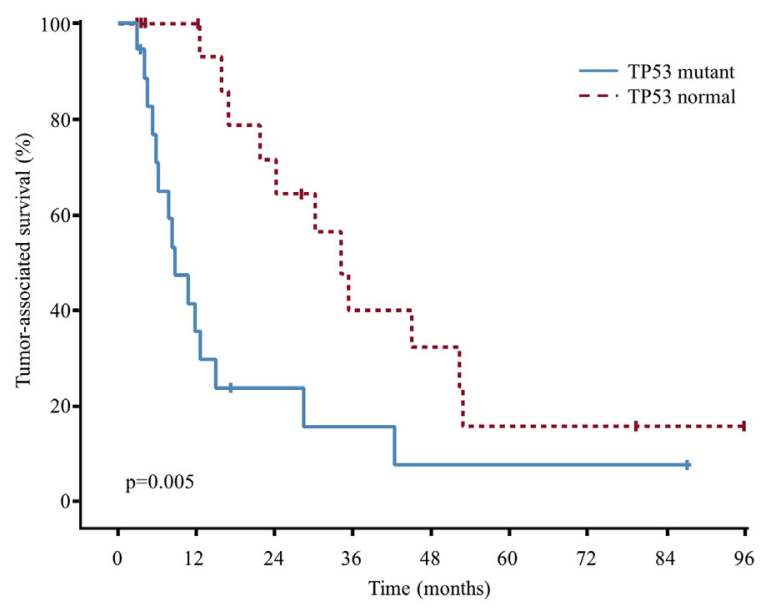

Number at risk

TP53 mutant 18

TP53 normal 18

3

1

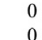

FIGURE 2. Tumor-associated survival in patients with normal TP53 versus mutant TP53

associations were observed between pathologic $\mathrm{T}$ stage and TP53 status (Table 3).

Regarding the reasons for not performing curative resection, they could be considered as informative for treatment response: One patient refused to undergo surgery after experiencing clinical $\mathrm{CR}$ at restaging. Eight patients presented with disease progression after neoadjuvant chemotherapy: 4 were inoperable due to local progression (confirmed by surgical exploration), 3 were inoperable due de novo distant metastases, and 1 had progressive disease and deemed unfit for surgery.

When we take the missing values as clinically informative and adapt them in that we considered the 8 patients without surgery due to disease progression as T4 (worst case), and the 1 patient who refused surgery due to clinical $\mathrm{CR}$ as $\mathrm{T0}$ (best case), the statistical test shows a significant association between pathologic tumor stage and TP53 mutation status $(P=.0191)$.

\section{DISCUSSION}

A markedly different survival after neoadjuvant chemotherapy was observed comparing patients with TP53 normal and TP53 mutant esophageal cancer, suggesting a lack of response to neoadjuvant cisplatin/fluorouracil in the population with mutant TP53.

Overall the observed median survival (13.9 months) and 2-year survival rate $(36.1 \%)$ conformed with results from 2 published clinical trials, ${ }^{7,9}$ namely the US Intergroup trial and the British Medical Research Council trial, which had applied comparable neoadjuvant regimens and patient selection criteria.

Stratification by TP53 marker status revealed a markedly different survival in the 2 marker groups: TP53 normal patients showed a median overall survival of 26.2 months and a 2-year overall survival rate of $55.6 \%$, compared with 8.6 months and $16.7 \%$ in patients with mutant TP53.

There are several studies evaluating the correlation of TP53 status and response to chemo/radio therapy in esophageal cancer: A recent meta-analysis comprising 1497 cases from 28 studies concluded that normal TP53 was associated with high response to chemotherapy-based treatment in esophageal cancer. ${ }^{10} \mathrm{By}$ its nature a meta-analysis is not homogenous for treatments, patient selection, and particularly for the p53 assays (several studies used p53 immunohistochemistry). Nevertheless the HR for pathologic major response was reported to be 1.15 (95\% CI, 1.06-1.25; $P=.001$ ). Our study, which is unique in that it uses for the first time a standardized, p53-specific sequencing analysis, and thereby avoids the possibility of missing of mutations, showed an HR for tumor-associated survival of 3.01 (95\% CI, 1.36-6.86).

Other published reports addressing the clinical significance of p53 have been inconsistent. ${ }^{11,12}$ Methodologic limitations such as the use of p53 immunohistochemistry or incomplete sequencing may account for these conflicting results. For esophageal cancer it has been explicitly shown that p53 immunohistochemistry does not correlate with response to chemotherapy, curative resection rate, or prognosis, whereas data from TP53 mutation analyses are more consistent concerning the association of TP53 mutation and poor survival. ${ }^{13-15}$ To date it is not clear if poorer prognosis or poorer response to chemotherapy is the reason for the survival disadvantage in patients with mutant TP53.

The objective tumor response observed in our study suggests a lack of response to neoadjuvant therapy in the population with mutant TP53. Fourteen of 18 patients with TP53 mutations had stable or progressive disease. On the other hand, CR was observed only in patients with normal TP53.

The multiple Cox model indicated that TP53 prognosed survival independently from established prognostic markers. However this model is based on a small sample size and model instability cannot be excluded. Because TP53 showed significant effects despite these heavily overfitted models, this is an indicator that TP53 might be an independent prognostic factor.

\section{Study Limitations}

It should be noted that our study lacked a surgery-only arm. Therefore we can only speculate that TP53 may be useful as a predictor of response to neoadjuvant therapy.

Assessment of objective tumor response in cancer therapy is a difficult issue. Comparisons of pretreatment with posttreatment staging bear limitations that need to be considered. The neoadjuvant setting of our study is advantageous in that it permits determination of pathologic response in resected specimens, which is considered more accurate than imaging. But as demonstrated, patients who cannot undergo resection due to disease progression during chemotherapy create missing values for pathologic staging. 
However from the clinical point of view progression during chemotherapy resulting in inoperability is very informative, because it indicates treatment failure. Thus ignorance of this information can bias the results because patients with treatment failure are excluded from analysis. Therefore, we adapted the missing values for an additional calculation in Table 3 (adapted pathologic tumor staging), and could demonstrate that posttreatment staging was significantly worse for the populations with mutated TP53.

Another problem when dealing with objective tumor response is the inaccuracy of imaging, a problem that may be aggravated by chemotherapy. ${ }^{16}$ The Response Evaluation Criteria In Solid Tumors criteria aimed to standardize tumor measurements and response reporting. ${ }^{17}$

Availability of pathologic tumor staging in neoadjuvant therapy studies reveals that the inaccuracy of clinical staging is still a problem and cannot be eliminated completely even with the integration of advanced technology like endoscopic ultrasound and fluordeoxyglucose PET or (better still) PET-computed tomography.

Many anticancer treatments fail to induce substantial benefits. It has been said that "over the last decade, the use of overall survival as primary endpoint has decreased significantly in clinical trials, as has the magnitude of benefit deemed clinically relevant." ${ }^{\prime 18}$ Molecular markers are expected to generate significant survival differences. Our results seem to be consistent with these expectations. In contrast to tumor response, survival can be assessed accurately and calculated to the day. ${ }^{19-21}$ Today we notice that with the implementation of molecular markers overall survival regains importance for demonstrating a benefit from treatment. ${ }^{20}$ As a consequence molecular markers are expected to raise the bar for clinical trials.

\section{FUTURE ANALYSES}

The Neoadjuvant Chemoradiation Followed by Surgery versus Surgery Alone for Patients with Adenocarcinoma or Squamous Cell Carcinoma of the Esophagus (CROSS) trial probably addresses the most effective treatment for esophageal cancer to date, but the data may not be useful for retrospective evaluation of a biomarker like TP53. In the CROSS trial, neoadjuvant treatment consisted of weekly carboplatin plus paclitaxel and concurrent radiotherapy. ${ }^{22}$ Carboplatin and radiation are likely to act via a p53controlled pathway-a hypothesis that we were able to validate in a number of clinical studies. ${ }^{23-26}$ But docetaxel acts differently and it is not clear if and how it interacts with TP53. ${ }^{27,28}$ Thus, due to the combination of these differential acting treatments in the CROSS trial, findings may be difficult to interpret when the population is stratified by TP53 status. $^{29}$

To answer the question if and how TP53 interacts with different classes of chemotherapy drugs in esophageal cancer, we conducted a prospective randomized trial, the
p53-Adjusted Neoadjuvant Chemotherapy for Potentially Resectable Esophageal Cancer (PANCHO) trial.* The trial was designed according to the "marker by treatment interaction design" recommended by Sargent and colleagues ${ }^{30}$ as a suitable design to answer a predictive biomarker question. In the PANCHO trial, patients with resectable esophageal cancer were stratified on the basis of the biomarker TP53 and subsequently randomized to different neoadjuvant treatments (cisplatin/fluorouracil vs docetaxel monotherapy). Recruitment for the PANCHO trial was recently completed; the data are awaited.

\section{CONCLUSIONS}

In patients with esophageal cancer a markedly differential survival after neoadjuvant chemotherapy could be demonstrated for the first time when comparing tumors with normal TP53 and tumors with mutant TP53. Our results suggest a lack of response to neoadjuvant cisplatin/ fluorouracil in the population with mutant TP53. Further studies are needed to validate our findings.

\section{References}

1. Sjoquist KM, Burmeister BH, Smithers BM, Zalcberg JR, Rj Simes, Barbour A, et al. Survival after neoadjuvant chemotherapy or chemoradiotherapy for resectable oesophageal carcinoma: an updated meta-analysis. Lancet Oncol. 2011;12: 681-92.

2. Donahue JM, Nichols FC, Li Z, Schomas DA, Allen MS, Cassivi SD, et al. Complete pathologic response after neoadjuvant chemoradiotherapy for esophageal cancer is associated with enhanced survival. Ann Thorac Surg. 2009;87:392-8; discussion 98-9

3. Vallbohmer D, Holscher AH, DeMeester S, DeMeester T, Salo J, Peters J, et al. A multicenter study of survival after neoadjuvant radiotherapy/chemotherapy and esophagectomy for ypTONOMOR0 esophageal cancer. Ann Surg. 2010;252: 744-9.

4. Lordick F. Optimizing neoadjuvant chemotherapy through the use of early response evaluation by positron emission tomography. Recent Results Cancer Res. 2012;196:201-11.

5. Weller M. Predicting response to cancer chemotherapy: the role of p53. Cell Tissue Res. 1998;292:435-45.

6. Petitjean A, Mathe E, Kato S, Ishioka C, Tavtigian SV, Hainaut P, et al. Impact of mutant p53 functional properties on TP53 mutation patterns and tumor phenotype: lessons from recent developments in the IARC TP53 database. Hum Mutat 2007;28:622-9.

7. Surgical resection with or without preoperative chemotherapy in oesophageal cancer: a randomised controlled trial. Lancet. 2002;359:1727-33.

8. den Dunnen JT, Antonarakis SE. Mutation nomenclature extensions and suggestions to describe complex mutations: a discussion. Hum Mutat. 2000;15:7-12.

9. Kelsen DP, Ginsberg R, Pajak TF, Sheahan DG, Gunderson L, Mortimer J, et al. Chemotherapy followed by surgery compared with surgery alone for localized esophageal cancer. N Engl J Med. 1998;339:1979-84.

10. Zhang SS, Huang QY, Yang H, Xie X, Luo KJ, Wen J, et al. Correlation of p53 status with the response to chemotherapy-based treatment in esophageal cancer: a meta-analysis. Ann Surg Oncol. 2013;20:2419-27.

11. Arsenijevic T, Micev M, Nikolic V, Gavrilovic D, Radulovic S, Pesko P. Is there a correlation between molecular markers and response to neoadjuvant chemoradiotherapy in locally advanced squamous cell esophageal cancer? J BUON 2012;17:706-11.

\footnotetext{
* The P53 Adapted Neoadjuvant Chemotherapy for Operable Esophageal Cancer (PANCHO) trial (www.clinicalTrials.gov identifier: NCT00525200; www.p53.at) is being conducted by the p53 Research Group and has successfully recruited 168 patients with primarily resectable esophageal cancer from 2007 to 2012 at 13 centers in Austria.
} 
12. Ressiot E, Dahan L, Liprandi A, Giorgi R, Djuorno XB, Padovani L, et al. Predictive factors of the response to chemoradiotherapy in esophageal cancer. Gastroenterol Clin Biol. 2008;32:567-77.

13. Makino T, Yamasaki M, Miyata H, Yosioka S, Takiguchi S, Fujiwara Y, et al. p53 Mutation status predicts pathological response to chemoradiotherapy in locally advanced esophageal cancer. Ann Surg Oncol. 2010;17:804-11.

14. Yamasaki M, Miyata H, Fujiwara Y, Takiguchi S, Nakajima K, Nishida T, et al. p53 genotype predicts response to chemotherapy in patients with squamous cell carcinoma of the esophagus. Ann Surg Oncol. 2010;17:634-42.

15. Madani K, Zhao R, Lim HJ, Casson AG. Prognostic value of p53 mutations in oesophageal adenocarcinoma: final results of a 15-year prospective study. Eur J Cardiothorac Surg. 2010;37:1427-32.

16. Flamen P, Lerut A, Van Cutsem E, Cambler JP, Maes A, De Wever W, et al. The utility of positron emission tomography for the diagnosis and staging of recurrent esophageal cancer. J Thorac Cardiovasc Surg. 2000;120:1085-92.

17. Liu Y, Litiere S, de Vries EG, Sargent D, Shankar L, Bogaerts J, et al. The role of response evaluation criteria in solid tumour in anticancer treatment evaluation: results of a survey in the oncology community. Eur J Cancer. 2014;50:260-6.

18. Sacher AG, Le LW, Leighl NB. Shifting patterns in the interpretation of phase III clinical trial outcomes in advanced non-small-cell lung cancer: the bar is dropping. J Clin Oncol. 2014;3:1407-11.

19. Ellis LM, Bernstein DS, Voest EE, Berlin JD, Sargent D, Cortazar P, et al. American Society of Clinical Oncology perspective: raising the bar for clinical trials by defining clinically meaningful outcomes. J Clin Oncol. 2014;32:1277-80.

20. Pazdur R. Endpoints for assessing drug activity in clinical trials. Oncologist. 2008;13(Suppl 2):19-21.

21. Therasse P, Arbuck SG, Eisenhauer EA, Wanders J, Kaplan RS, Rubinstein L, et al. New guidelines to evaluate the response to treatment in solid tumors. European Organization for Research and Treatment of Cancer, National Cancer Institute of the United States, National Cancer Institute of Canada. J Natl Cancer Inst. 2000;92:205-16.
22. van Hagen P, Hulshof MC, van Lanschot JJ, Steyerberg EW, van Berge Henegouwen MI, Wijnhoven BP, et al, CROSS Group. Preoperative chemoradiotherapy for esophageal or junctional cancer. N Engl J Med. 2012;366:2074-84.

23. Kandioler D, Stamatis G, Eberhardt W, Kappel S, Zöchbauer-Müller S, Kührer I, et al. Growing clinical evidence for the interaction of the p53 genotype and response to induction chemotherapy in advanced non-small cell lung cancer. $J$ Thorac Cardiovasc Surg. 2008; 135:1036-41.

24. Kandioler D, Zwrtek R, Ludwig C, Janschek E, Ploner M, Hofbauer F, et al. TP53 genotype but not p53 immunohistochemical result predicts response to preoperative short-term radiotherapy in rectal cancer. Ann Surg. 2002;235:493-8.

25. Kandioler-Eckersberger D, Kappel S, Mittlbock M, Dekan G, Ludwig C, Janschek E, et al. The TP53 genotype but not immunohistochemical result is predictive of response to cisplatin-based neoadjuvant therapy in stage III non-small cell lung cancer. J Thorac Cardiovasc Surg. 1999;117:744-50.

26. Kandioler-Eckersberger D, Ludwig C, Rudas M, Kappel S, Janschek E, Wnzel C, et al. TP53 mutation and p53 overexpression for prediction of response to neoadjuvant treatment in breast cancer patients. Clin Cancer Res. 2000;6:50-6.

27. Bonnefoi H, Piccart M, Bogaerts J, Mauriac L, Fumoleau P, Brain E, et al. TP53 status for prediction of sensitivity to taxane versus non-taxane neoadjuvant chemotherapy in breast cancer (EORTC 10994/BIG 1-00): a randomised phase 3 trial. Lancet Oncol. 2011;12:527-39.

28. Di Leo A, Tanner M, Desmedt C, Paesmans M, Cardoso F, Durbecq V, et al. p-53 gene mutations as a predictive marker in a population of advanced breast cancer patients randomly treated with doxorubicin or docetaxel in the context of a phase III clinical trial. Ann Oncol. 2007;18:997-1003.

29. Simon R. Guidelines for the design of clinical studies for the development and validation of therapeutically relevant biomarkers and biomarker-based classification systems. In: Hayes G, ed. Biomarkers in breast cancer. Totowa: Humana Press; 2006:3-15.

30. Sargent DJ, Conley BA, Allegra C, Collette L. Clinical trial designs for predictive marker validation in cancer treatment trials. J Clin Oncol. 2005;23:2020-7.

\section{EDITORIAL COMMENTARY}

\section{Predicting response to neoadjuvant therapy in esophageal cancer with p53 genotyping: A fortune-teller's crystal ball or a viable prognostic tool?}

Katie S. Nason, MD, MPH

See related article on pages 2280-6.

Ideally, predictive biomarkers with associated targeted therapies would be available for individualized treatment of esophageal cancer, optimizing outcome and minimizing

From the Division of Thoracic and Foregut Surgery, Department of Cardiothoracic Surgery, University of Pittsburgh, Pittsburgh, Pa.

Dr Nason's work is supported by Grant K07CA151613 from the National Cancer Institute.

Disclosures: Author has nothing to disclose with regard to commercial support. Received for publication Sept 14, 2014; accepted for publication Sept 15, 2014

Address for reprints: Katie S. Nason, MD, MPH, University of Pittsburgh, 5200

Centre Ave, Suite 715, Shadyside Medical Building, Pittsburgh, PA 15232

(E-mail: nasonks@upmc.edu).

J Thorac Cardiovasc Surg 2014;148:2286-7

0022-5223/\$36.00

Copyright (c) 2014 by The American Association for Thoracic Surgery

http://dx.doi.org/10.1016/j.jtcvs.2014.09.036 chemotherapy-associated risks. Unfortunately, clinically relevant biomarker identification for esophageal cancer has been elusive, more often resembling predictions from a fortune-teller's crystal ball than proving to be valid, clinically useful prognostic tools. The quest continues, however, and the p53 (TP53) gene appears promising. One of the most frequently mutated cancer-associated genes and a critical tumor suppressor gene involved in programed cell death, ${ }^{1}$ multiple studies show a relationship between TP53 mutation and response to chemotherapy, including that of esophageal cancer. A recent meta-analysis of 28 studies with 1497 patients by Zhang and colleagues ${ }^{2}$ showed high response rates to chemotherapy-based treatment regimens in tumors with low p53 protein expression or wild-type p53. Despite statistically significant findings, however, the conclusions were limited by tremendous heterogeneity across studies with respect to assessment of therapeutic response, chemotherapy regimens (dose and type), 